\title{
Physical and Electrolytic Properties of Monofluorinated Ethyl Acetates and Their Application to Lithium Secondary Batteries
}

\author{
Noritoshi Nambu*, Yukio Sasaki \\ Department of Life Science and Sustainable Chemistry, Faculty of Engineering, Tokyo Polytechnic University, \\ Atsugi, Kanagawa, Japan \\ Email: ${ }^{\text {nanbu@chem.t-kougei.ac.jp }}$
}

Received 16 March 2015; accepted 26 April 2015; published 30 April 2015

Copyright (C) 2015 by authors and Scientific Research Publishing Inc.

This work is licensed under the Creative Commons Attribution International License (CC BY). http://creativecommons.org/licenses/by/4.0/

cc) (i) Open Access

\begin{abstract}
Ethyl acetate (EA) shows low viscosity for its relative permittivity. Monofluorinated organic solvents exert the polar effect on the various properties. We have investigated the effect of position isomerism on the physical and electrochemical properties of two monofluorinated carboxylates: 2-fluoroethyl acetate (2FEA) and ethyl fluoroacetate (EFA). Relative permittivity of 2FEA was lower than that of EFA, whereas viscosity of 2 FEA was higher. Electrolytic conductivity of a LiPF 6 solution in 2FEA was lower than that in EFA, but higher than that in EA at high temperatures. The use of 2FEA as a co-solvent improved cycling efficiency and suppressed fading of discharge capacity of a $\mathrm{Li} \mid \mathrm{LiCoO}_{2}$ coin cell at high cycle numbers.
\end{abstract}

\section{Keywords}

Monofluorinated Organic Solvent, Carboxylate, Position Isomerism, Electrolytic Properties, Discharge Capacity, Lithium Secondary Battery

\section{Introduction}

Ethyl acetate is a carboxylate ester of ethanol and acetic acid and is commonly abbreviated to EA or EtOAc. This colorless liquid has a characteristic sweet smell (similar to pear drops). EA is used as a solvent for chemical reactions. EA is often used in cosmetics because of its odor, and its smell is associated with nail polishes. Furthermore, EA is used in confectionery, perfumes, and fruits because it evaporates at a fast rate, leaving but the scent of the perfume on the skin.

${ }^{*}$ Corresponding author.

How to cite this paper: Nambu, N. and Sasaki, Y. (2015) Physical and Electrolytic Properties of Monofluorinated Ethyl Acetates and Their Application to Lithium Secondary Batteries. Open Journal of Metal, 5, 1-9. 
EA is one of the linear carboxylates. EA shows high relative permittivity $\left(\varepsilon_{\mathrm{r}}=6.02\right.$ at $\left.25^{\circ} \mathrm{C}\right)$, but low viscosity $\left(\eta=0.426 \mathrm{mPa} \mathrm{s}\right.$ at $\left.25^{\circ} \mathrm{C}\right)[1]$, as compared to dimethyl carbonate (DMC) $\left(\varepsilon_{\mathrm{r}}=3.12\right.$ and $\eta=0.63 \mathrm{mPa} \mathrm{s}$ at $\left.25^{\circ} \mathrm{C}\right)$, ethyl methyl carbonate (EMC) $\left(\varepsilon_{\mathrm{r}}=2.93\right.$ and $\eta=0.68 \mathrm{mPa} \mathrm{s}$ at $\left.25^{\circ} \mathrm{C}\right)$, and diethyl carbonate (DEC) $\left(\varepsilon_{\mathrm{r}}=2.82\right.$ and $\eta=0.75 \mathrm{mPa}$ at $25^{\circ} \mathrm{C}$ ). These three linear carbonates are commonly used as low-viscosity solvents for lithium-ion batteries [2] [3]. In contrast, ethylene carbonate (EC) is a cyclic carbonate and is used as a high-polarity solvent for lithium-ion batteries [2] [3].

The use of linear carboxylates as alternative solvents can decrease the internal resistance of lithium batteries. However, the potentials for the oxidation decomposition of linear carboxylates (3.4 V vs. SCE for methyl acetate and methyl propionate [4]) are lower than those of linear carbonates (3.7 V vs. SCE for DMC, EMC, and DEC [4]). Partially fluorinated carbonates exert the polar effect on the physical and electrochemical properties such as relative permittivity, viscosity, electrolytic conductivity, and electrochemical stability [5]-[11]. Monofluorination of EA and ethyl propionate (EP) improved the anodic stability [12] [13]. Methyl difluoroacetate is known as an excellent additive for lithium batteries [2] [14]-[18].

2-Fluoroethyl acetate (2FEA) and ethyl fluoroacetate (EFA) are isomeric with each other: structural isomerism, which is especially called position isomerism. Figure 1 compares the structures of 2FEA, EFA, EA, and EMC. In this paper, we describe the temperature dependence of the mass densities, molar concentrations, relative permittivities, and viscosities of 2FEA, EFA, EA, and EMC in some detail. Furthermore, we report the conductivities of electrolyte solutions in 2FEA, EFA, EA, and EMC and their application to lithium secondary batteries.

\section{Experimental}

The synthesis and purification of 2FEA are described in the previous paper [12]. The apparatus and techniques for measurements are essentially the same as those previously reported [6] [10].

Relative permittivities $\left(\varepsilon_{\mathrm{r}}\right)$ or relative dielectric constants were measured with a LF impedance analyzer (Hewlett Packard, 4192A) connected to a thermostat (Ando Denki, TO-9). The electrostatic capacitances of air $\left(C_{0}\right)$ and a sample $\left(C_{\text {sample }}\right)$ were measured at a frequency of $1 \mathrm{MHz}$, and the relative permittivity can be adequately approximated by the ratio $\left(\varepsilon_{\mathrm{r}} \approx C_{\text {sample }} / C_{0}\right)$. The samples were sufficiently deaerated by bubbling $\operatorname{Ar}$ gas $(99.9 \%)$ before the measurement.

Kinematic viscosities $(v)$ were measured with a capillary-tube viscometer, Ostwald viscometer (Shibayama Scientific Co., Ltd., SS-290S), equipped with a thermostat. Silicone oil was circulated in the constant-temperature bath. Viscosity $(\eta)$ or viscosity coefficient can be expressed as the product of the kinematic viscosity and the mass density $(\eta=v \cdot d)$; the kinematic viscosity is defined as the ratio of the viscosity to the mass density of a fluid $(v=\eta / d)$ and is directly proportional to the time required for the liquid to flow through a capillary-tube viscometer under its own hydrostatic head. Mass densities $(d)$ were measured by the use of a density/specific gravity meter (Kyoto Electronics Manufacturing Co., Ltd., DA-505). The physical constants of organic solvents were measured from $10^{\circ} \mathrm{C}$ to $70^{\circ} \mathrm{C}$.

Conductivities of electrolyte solutions were measured by use of a conductometer (Toa Electronics Inc., Model CM-60S) equipped with the cell (Model CGT-511B) from $-5^{\circ} \mathrm{C}$ to $70^{\circ} \mathrm{C}$.

Linear potential sweep voltammetry (LSV) was performed with a platinum electrode, $1.6 \mathrm{~mm}$ in diameter, on a computer-controlled electrochemical system (Solartron Analytical, type SI1287) at a sweep rate of $5 \mathrm{mVs}^{-1}$.<smiles>CC(=O)OCCF</smiles>

Ethyl acetate (EA)<smiles>CCOC(C)=O</smiles><smiles>CCOC(=O)F</smiles>

Ethyl methyl carbonate (EMC)<smiles>CCOC(=O)OC</smiles>

Figure 1. Structures of 2FEA, EFA, EA, and EMC. 
Lithium foil and a platinum wire were used as the reference and the auxiliary electrodes, respectively.

Coulometric efficiency achieved with the repetitiveness of the deposition and dissolution of lithium on a nickel electrode (cycling efficiency of a lithium anode) was measured with a charge/discharge unit (Hokuto Denko Corp., Model HJ-201B). Three-electrode cells were used for the measurement of the cycling efficiency. Lithium foil was employed as the auxiliary and the reference electrodes. The cycling efficiency was estimated by a galvanostatic plating/stripping method reported by Koch and Brummer [19]. The plating and the stripping current densities were set at $\pm 1 \mathrm{mAcm}^{-2}$. The plated charge density was adjusted to $-300 \mathrm{mCcm}^{-2}$, and the cutoff voltage was set at $+1.0 \mathrm{~V}$ vs. $\mathrm{Li} \mid \mathrm{Li}^{+}$during the anodic stripping. A 2025-type coin cell (can size: $20 \mathrm{~mm}$ in diameter and $2.5 \mathrm{~mm}$ in thickness, stainless steel body) was assembled with a $\mathrm{LiCoO}_{2}$ sheet cathode $(16 \mathrm{~mm}$ in diameter), a lithium-metal sheet anode (16 mm in diameter), a separator (Celgard Inc., \#3501), and the test solution. The discharge capacities of the $\mathrm{Li} \mid \mathrm{LiCoO}_{2}$ coin cells were measured with a 6-channel charge/discharge unit (Hokuto Denko Corp., Model HJ-101SM6). The coin cells were charged in a constant current (1 C)-constant voltage $(4.2 \mathrm{~V})$ regime at $25^{\circ} \mathrm{C}$ until total charge time reached $1 \mathrm{~h}$. Afterwards, they were discharged to $3.0 \mathrm{~V}$ at the inverse current of $1 \mathrm{C}$.

The preparation of electrolyte solutions and the fabrication of three-electrode cells and coin cells were carried out in an argon-filled glove box system made by VAC. The concentrations of $\mathrm{O}_{2}$ and $\mathrm{H}_{2} \mathrm{O}$ were kept less than 1 ppm in the glove box.

The morphology of the films formed on the Ni (working) electrode after cycling was observed by using a scanning electron microscope (SEM, JSM-5310).

\section{Results and Discussion}

\subsection{Physical Properties of Solvents}

Figure 2 shows the temperature $(\theta)$ dependence of (a) mass densities $(d)$ and (b) molar concentrations $(c)$ of 2FEA, EFA, and EA single solvents. In addition, this figure compares data for EMC, whose structure is similar to that of EA. The mass densities and molar concentrations of the linear carboxylates and EMC decreased with an increase in temperature. The plots of the mass density and molar concentration against temperature were slightly curved. The molar concentration was calculated from the mass density and the molar mass $(M)$ according to the following equation:

$$
c=\frac{d}{M}
$$

The molar concentration decreased in the following descending order: 2FEA $>$ EFA $>$ EA $>$ EMC. The molar concentration dominated the order of the mass densities of EA and its derivatives: 2FEA $>$ EFA ( $>$ EMC) $>$ EA. As a result of the combined effect of the high molar mass and the high molar concentration, the mass densities of 2FEA and FEA were higher than that of EA.

Monofluorination of EA increased the mass and volume of the molecule. Since 2FEA and EFA are position

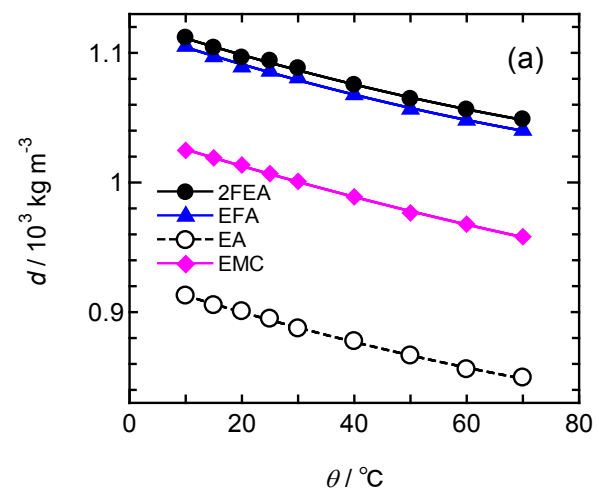

(a)

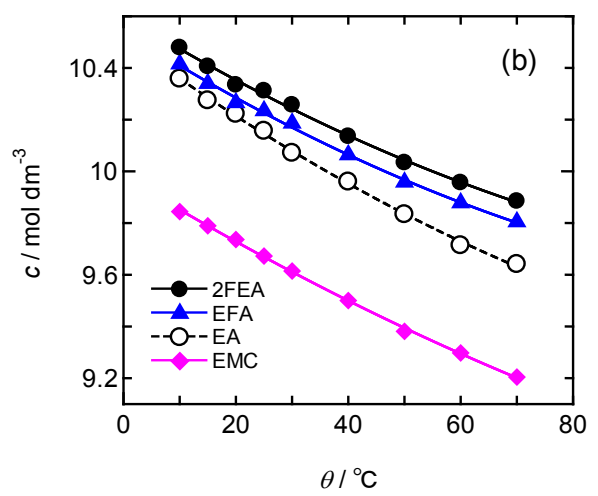

(b)

Figure 2. (a) Mass densities $(d)$ and (b) molar concentrations (c) of 2FEA, EFA, and EA single solvents as a function of temperature $(\theta)$ from $10^{\circ} \mathrm{C}$ to $70^{\circ} \mathrm{C}$. Included in this figure for comparison are data for $1 \mathrm{~mol} \mathrm{dm}^{-3} \mathrm{LiPF} 6$ solution in EMC. 
isomerism, the values of the relative molecular mass are equal to each other $\left(M_{\mathrm{r}}=106.10\right)$. Taft's steric substituent constants $\left(E_{\mathrm{S}}\right)$ are a measure of steric effects of aliphatic substituents [20]. A large negative value of $E_{\mathrm{S}}$ means a bigger steric effect. A fluoromethyl group $\left(\mathrm{CH}_{2} \mathrm{~F}-\right)\left(E_{\mathrm{S}}=-0.24\right)$ is somewhat larger than a methyl group $\left(\mathrm{CH}_{3}-\right)\left(E_{\mathrm{S}}=0.00\right)$. The value of -0.24 is comparable with a chloromethyl group $\left(\mathrm{CH}_{2} \mathrm{Cl}-\right)\left(E_{\mathrm{S}}=-0.24\right)$. Interestingly, the molar concentrations of 2FEA and EFA were higher than that of EA in spite of the increased molecular volume. The molar concentration reflects both the strength of the attractive forces and the reverse of the molar volume. The volume of the monofluorinated EAs contracts to some extent because of the attractive forces between molecules, and consequently the molar concentration increases. The attraction of 2FEA and EFA molecules can be based on nonconventional weak intermolecular hydrogen bonding $(\mathrm{CF}-\mathrm{H} \cdots \mathrm{O}=\mathrm{C}$ or $\mathrm{C}-\mathrm{H} \cdots \mathrm{F}-\mathrm{C})$ [20] as well as conventional dipole-dipole interactions. The weak hydrogen-bonding system does not exchange its proton and therefore it is no more a genuine hydrogen bond; it is an electrostatic attraction of positive charge on the hydrogen and negative charge on the organic fluorine or the organic oxygen [20]. A 2-fluoroethoxy $\left(\mathrm{CH}_{2} \mathrm{FCH}_{2} \mathrm{O}-\right)$ group in a $2 \mathrm{FEA}$ molecule can form the intermolecular hydrogen bonds $(\mathrm{CF}-\mathrm{H} \cdots \mathrm{O}=\mathrm{C}$ or $\mathrm{C}-\mathrm{H} \cdots \mathrm{F}-\mathrm{C})$ more effectively than a fluoroacetyl $\left(\mathrm{CH}_{2} \mathrm{FCO}-\right)$ group in an EFA molecule. Therefore, the molar concentration of 2FEA became higher than that of EFA.

Figure 3 shows the temperature $(\theta$ or $T)$ dependence of (a) relative permittivity $\left(\varepsilon_{\mathrm{r}}\right)$ and (b) viscosity $(\eta)$ of 2FEA, EFA, and EA single solvents. In addition, this figure compares data for EMC, whose structure is similar to that of EA. The relative permittivity reflects the ease of dielectric polarization. The relative permittivity has a very significant effect on the strength of the interactions between ions especially in dilute solutions. The viscosity is regarded as internal friction based on intermolecular forces and affects electrolytic conductivity. Both the relative permittivity and the viscosity depend on the molar concentration. The relative permittivity of EA was more than twice that of EMC in spite of its low viscosity. Monofluorination of EA increased both the relative permittivity and the viscosity. It should be noted that the relative permittivity of EFA was higher than that of 2FEA, but that the viscosity of EFA was lower than anticipated from the relative permittivity: EFA $>2$ FEA $>$ $\mathrm{EA}>$ EMC for the relative permittivity and 2FEA $>$ EFA $>$ EMC $>$ EA for the viscosity.

The amount of orientation polarization of EFA was larger than that for $2 \mathrm{FEA}$. An acetyl group $\left(\mathrm{CH}_{3} \mathrm{CO}-\right)$ is more electron-withdrawing and more rigid than an ethoxy group $\left(\mathrm{CH}_{3} \mathrm{CH}_{2} \mathrm{O}-\right)$. Monofluorination of the acetyl group can make the opposite large charges separated in the molecule, and hence induce the large bond moment. The net dipole moment of the EFA molecule may be larger than that of the 2FEA molecule. In contrast, the molar concentration of 2FEA was higher than those of EFA and EA because of the contraction in volume, as described above. The internal friction of 2FEA can increase under these circumstances, and accordingly the viscosity of 2FEA became higher.

The viscosity decreased exponentially with an increase in temperature, and plots of $\log _{10}(\eta / \mathrm{mPa} s)$ vs. $T^{-1}$ gave straight lines. The high translational kinetic energy allows intermolecular attractions to be overcome more easily, and the internal friction is reduced at high temperatures. The apparent activation energy for viscosity $\left(E_{\mathrm{a}, \eta}\right)$ is obtained from the relation proposed by Andrade [21]:

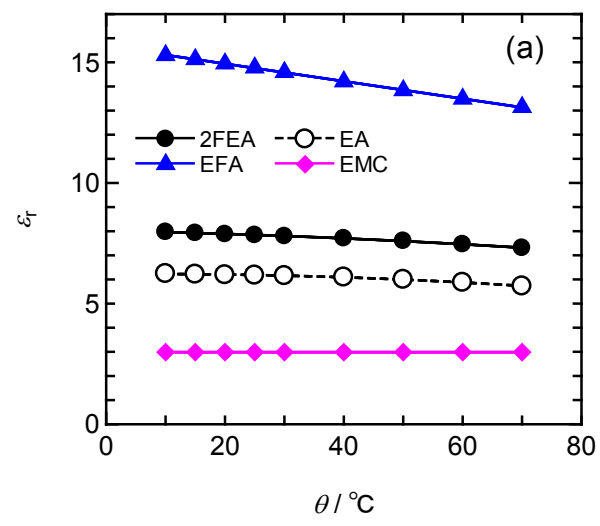

(a)

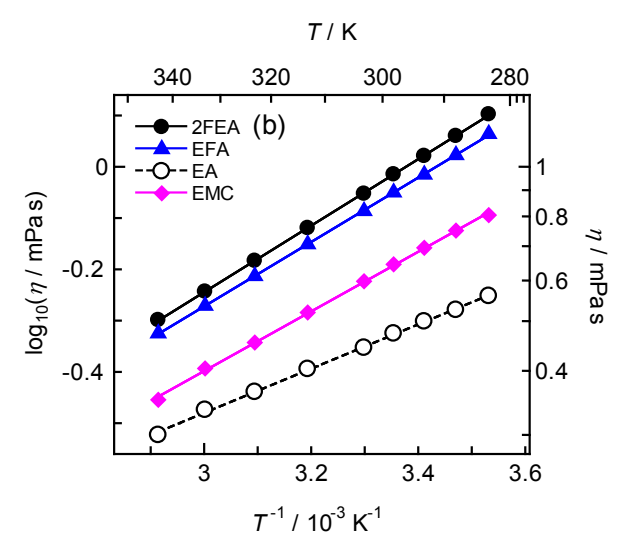

(b)

Figure 3. (a) Relative permittivities $\left(\varepsilon_{\mathrm{r}}\right)$ and (b) viscosities $(\eta)$ of 2FEA, EFA, EA, and EMC single solvents as a function of temperature $(\theta$ or $T)$ from $10^{\circ} \mathrm{C}(283.15 \mathrm{~K})$ to $70^{\circ} \mathrm{C}(343.15 \mathrm{~K})$. 


$$
\eta=A_{\eta} \exp \left(\frac{E_{\mathrm{a}, \eta}}{R T}\right)
$$

The apparent activation energy is determined to be $12.41,12.02,11.13$, and $8.258 \mathrm{kJmol}^{-1}$ for $2 \mathrm{FEA}$, EFA, EMC, and EA, respectively. The viscosity and apparent activation energy of monofluorinated EAs were higher than those of EA and EMC. The apparent activation energy decreased in the same order as the viscosity: 2FEA > $\mathrm{EFA}>\mathrm{EMC}>\mathrm{EA}$.

\subsection{Electrolytic Conductivities of LiPF 6 Solutions}

Electrolytic conductivity of a solution is a key factor determining the internal resistance and rate performance of a battery. Figure 4(a) shows the temperature ( $T$ or $\theta$ ) dependence of electrolytic conductivities $(\kappa)$ of $1 \mathrm{moldm}^{-3}$ $\mathrm{LiPF}_{6}$ solutions in 2FEA, EFA, and EA. Included in this figure for comparison are data for $1 \mathrm{~mol} \mathrm{dm}^{-3} \mathrm{LiPF}_{6}$ solution in EMC. The conductivities of the electrolyte solutions increased with an increase in temperature. The viscosities of these solvents decreased rapidly at elevated temperatures. The decrease in the relative permittivity at high temperatures would not so much influence the conductivity. The conductivity can be affected by the ionic mobility, the charge numbers of the ions, the concentration of the electrolyte, the degree of ionic dissociation, etc. The ionic mobility is related to the viscosity of the electrolyte solution. The degree of ionic dissociation of a lithium salt is set by the balance between the permittivity and Lewis basicity of the medium, depending on the concentration of the lithium salt [10].

The electrolytic conductivity of an EA solution was more than twice that of an EMC counterpart. The relative permittivity of EFA was higher than that of 2FEA, whereas the viscosity of EFA was lower. Therefore, the high ionic mobility and the high degree of ionic dissociation produce a synergy effect on the conductivity of an EFA solution. The conductivity of an EFA solution was higher than that of a 2FEA counterpart over a temperature range of $-5^{\circ} \mathrm{C}$ to $70^{\circ} \mathrm{C}$. The introduction of a fluorine atom into an EA molecule may decrease the electron-pair donability of oxygen atoms in the -COO- moiety. This effect results in the decreased solvation of lithium ions and, consequently, in the lower degree of ionic dissociation. In particular, the monofluorination of the ethoxy group may decrease Lewis basicity more greatly than that of the acetyl group. The drop in the basicity of 2FEA may be produced by the nonconventional hydrogen bonds. Steric hindrance between the -COO- moiety and the 2-fluoroethyl moiety may also weaken the basicity of 2FEA. The plots of $\log _{10}(\eta / \mathrm{mPa} s) \mathrm{vs} . T^{-1}$ gave straight lines, as shown in Figure 3(b). In contrast, the plots of $\log _{10}\left(\kappa / \mathrm{mScm}^{-1}\right)$ vs. $T^{-1}$ displayed upward curvature. The different features suggest that the conductivity does not vary inversely with the viscosity especially at elevated temperatures.

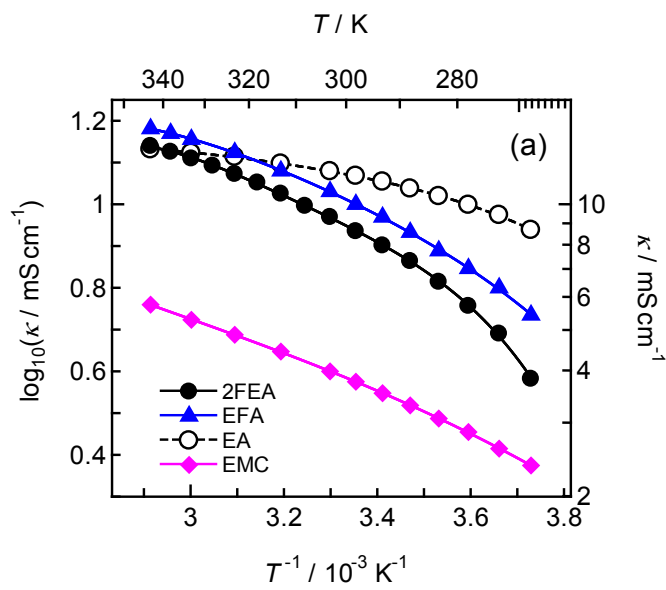

(a)

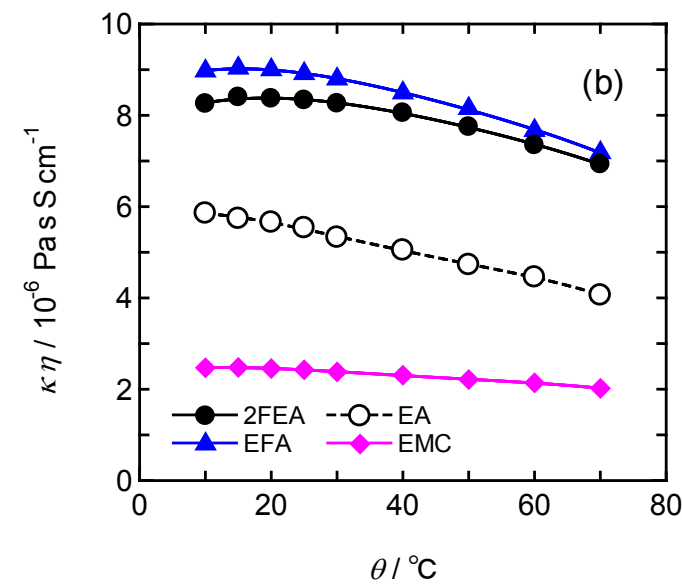

(b)

Figure 4. (a) Conductivities $(\kappa)$ of electrolyte solutions in 2FEA, EFA, EA, and EMC as a function of temperature $(T)$ from $-5^{\circ} \mathrm{C}(268.15 \mathrm{~K})$ to $70^{\circ} \mathrm{C}(343.15 \mathrm{~K})$. Electrolyte: $\mathrm{LiPF}_{6}\left(1 \mathrm{moldm}^{-3}\right.$ at $\left.25 \mathrm{C}\right)$. (b) The product of conductivity and viscosity $(\mathrm{k \eta})$ as a function of temperature $(\theta)$ from $10^{\circ} \mathrm{C}$ to $70^{\circ} \mathrm{C}$. We adopted the viscosities of the single solvents. Electrolyte solutions are the same as described in the caption of (a). 
There was intersection of the two plots of conductivity against temperature: about $65^{\circ} \mathrm{C}$ for $2 \mathrm{FEA}$ and EA solutions [12]; and about $47^{\circ} \mathrm{C}$ for EFA and EA solutions [12]. Consequently, the conductivity of an EFA solution was higher than that of the EA counterpart over a temperature range of $47^{\circ} \mathrm{C}-70^{\circ} \mathrm{C}$. The temperature range was wider than that observed for $2 \mathrm{FEA}\left(65^{\circ} \mathrm{C}-70^{\circ} \mathrm{C}\right)$. The threshold temperature, where monofluorination of an organic solvent leads to an increase in conductivity, is also observed for $1 \mathrm{moldm}^{-3} \mathrm{LiPF}_{6}$ solutions in other linear carboxylates and linear carbonates: about $50^{\circ} \mathrm{C}$ for 2-fluoroethyl propionate (2FEP) and ethyl propionate (EP) [13]; about $8^{\circ} \mathrm{C}$ for ethyl 3-fluoropropionate (E3FP) and $\mathrm{EP}$ [13]; about $2^{\circ} \mathrm{C}$ for ethyl 2-fluoropropionate (E2FP) and EP [13]; about $45^{\circ} \mathrm{C}$ for 2-fluoroethyl methyl carbonate (2FEMC) and EMC [5]; and about $25^{\circ} \mathrm{C}$ for ethyl 2-fluoroethyl carbonate (E2FEC) and DEC [7].

Figure 4(b) shows the temperature dependence of the product of conductivity and viscosity $(\kappa \eta)$. These plots are different from the so-called Walden products. The $\kappa \eta$ was slightly decreasing at high temperatures. The decrease in the $\kappa \eta$ and the presence of the threshold temperature support the idea that the conductivity is not inversely proportional to the viscosity especially at elevated temperatures.

\subsection{Electrochemical Stability and Cycling Efficiency of Lithium Anode}

Linear sweep voltammetry (LSV) was carried out to investigate electrochemical potential windows of electrolyte solutions. Figure 5(a) shows linear potential sweep voltammograms obtained with a platinum electrode for $1 \mathrm{moldm}^{-3} \mathrm{LiPF}_{6}$ solutions in $2 \mathrm{FEA}, \mathrm{EFA}, \mathrm{EA}$, and EMC at a scan rate of $5 \mathrm{mVs}^{-1}$ at $25^{\circ} \mathrm{C}$. Monofluorination of EA increased the anodic stability, as easily predicted by the highest electronegativity of fluorine.

Most conventional measures for the electronic effect of substituents are provided as Taft $\left(\sigma^{*}\right)$ constants for substituents attached to aliphatic chains [20]. The electron-withdrawing inductive effect of a fluorometheyl group $\left(\mathrm{CH}_{2} \mathrm{~F}-\right.$ : Taft $\left.\sigma^{*}=1.10\right)$ is substantially stronger than that of a metheyl group $\left(\mathrm{CH}_{3}\right.$-: Taft $\left.\sigma^{*}=0\right)$. Accordingly, the anodic stability of 2FEA and EFA was higher than that of EA. On the other hand, the anodic stability of 2FEA and EFA was slightly lower than that of EMC. We cannot determine the potentials for reduction decomposition of 2FEA, EFA, EA, and EMC in the potential range of $2-0 \mathrm{~V}$. Small anodic peaks at about $5.8 \mathrm{~V}$ and cathodic peaks in a potential range of $2 \mathrm{~V}$ to $3 \mathrm{~V}$ can be ascribed to degradation products of $\mathrm{LiPF}_{6}$ or impurities in 2FEA and EFA.

Cycling efficiency of a lithium anode indicates coulometric efficiency achieved with the repetitiveness of the deposition and dissolution of lithium on a nickel electrode. Figure 5(b) shows the variation of the cycling efficiency with respect to the cycle number at $25^{\circ} \mathrm{C}$. We used 1 moldm $^{-3} \mathrm{LiPF}_{6}$ solutions in EC-2FEA, EC-EFA,

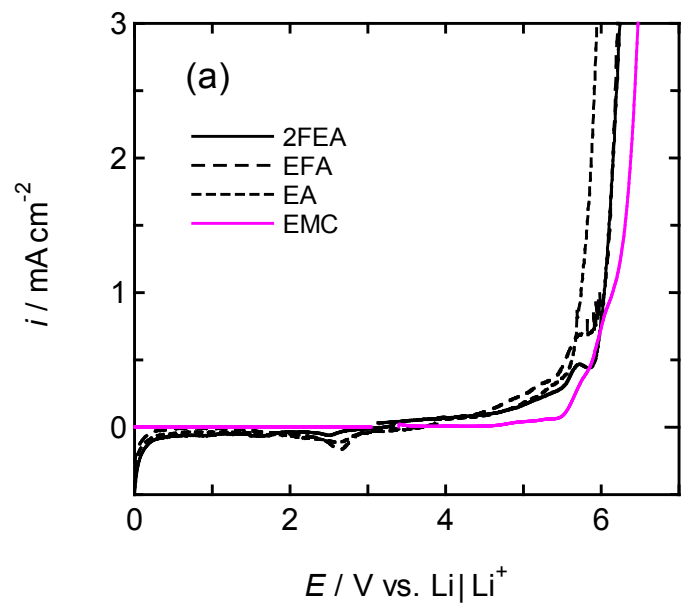

(a)

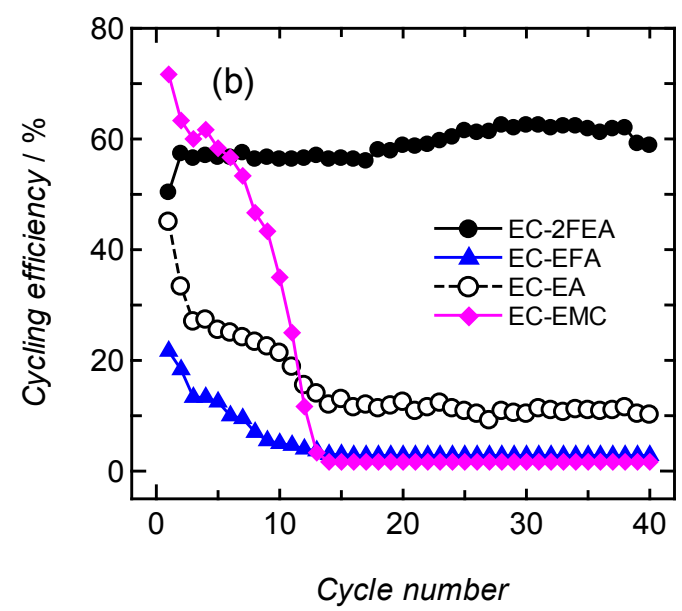

(b)

Figure 5. (a) Linear sweep voltammograms obtained with a platinum electrode for electrolyte solutions in 2FEA, EFA, EA, and $\mathrm{EMC}$ at a scan rate of $5 \mathrm{mVs}^{-1}$ at $25^{\circ} \mathrm{C}$. Electrolyte: $\operatorname{LiPF}_{6}\left(1 \mathrm{moldm}^{-3}\right)$. (b) Variation of cycling efficiency of lithium anodes with respect to the cycle number at $25^{\circ} \mathrm{C}$. Electrolyte solutions: 1 moldm $^{-3} \mathrm{LiPF}_{6}$ solutions in EC-2FEA, EC-EFA, EC-EA, and EC-EMC equimolar binary mixtures. The plating and the stripping current density were fixed at $\pm 1 \mathrm{mAcm}^{-2}$. The plated charge density was $-300 \mathrm{mCcm}^{-2}$, and the cut-off voltage was set to $+1.0 \mathrm{~V} \mathrm{vs}$. $\mathrm{Li}_{\mid} \mid \mathrm{Li}^{+}$during the anodic stripping process. 
and EC-EA equimolar binary mixtures as the electrolyte solutions. Included in Figure 5(b) for comparison are data for an EC-EMC equimolar binary mixture. The cycling efficiency was less than $20 \%$ in EC-EFA, EC-EA, and EC-EMC binary systems after the 12th cycle. The use of the EC-2FEA binary mixture remarkably suppressed the cycling efficiency fading. The morphology, thickness, density, and chemical composition of the surface film may be different from those of a surface film formed in a lithium anode|electrolyte solution interphase.

Figure 6 shows photographs obtained with scanning electron microscope (SEM) after the 10th deposition/ dissolution cycle of lithium. This figure shows that the morphology of the surface film was homogeneous in the EC-2FEA binary system (a). Furthermore, the surface film consisted of grains of small and regular size, and the thickness seemed to be relatively thin in this binary solvent system. In contrast, the morphology of the surface film was coarse and heterogeneous in the EC-EA binary system (c). Plank-type deposits, which might be lithium dendrite, were observed in this binary solvent system.

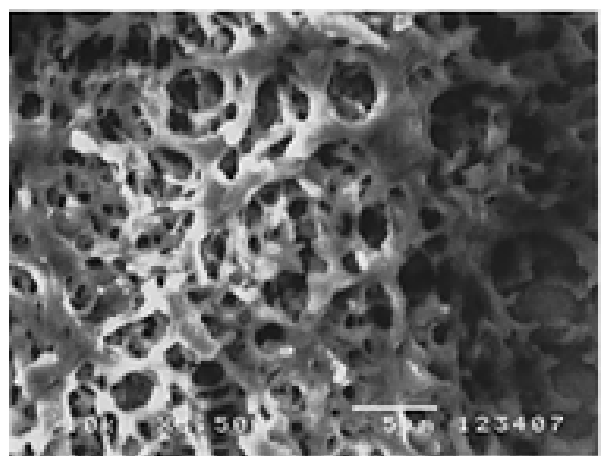

(a)

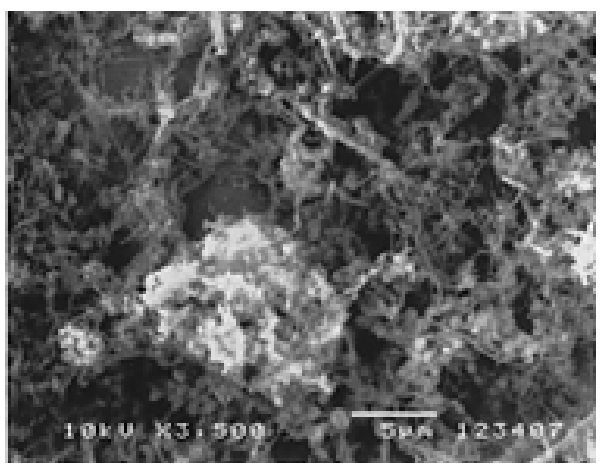

(b)

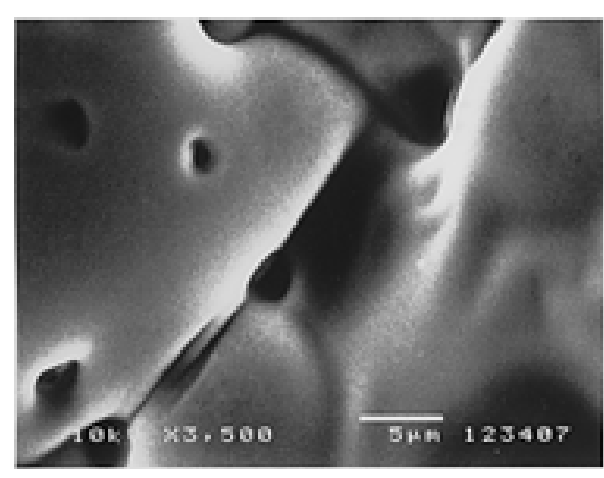

(c)

Figure 6. SEM photographs obtained after the 10th deposition/dissolution cycle of lithium on a nickel electrode. Electrolyte solutions: 1 moldm$^{-3} \mathrm{LiPF}_{6}$ solutions in (a) EC-2FEA, (b) EC-EFA, and (c) EC-EA equimolar binary mixtures.

\subsection{Performance of Li|LiCoO ${ }_{2}$ Coin Cells}

We assembled 2025-type coin cells to evaluate the performance by a charge-discharge test. Figure 7 shows the evolution of discharge capacities of $\mathrm{Li} \mid \mathrm{LiCoO}_{2}$ coin cells with respect to the cycle number at $25^{\circ} \mathrm{C}$. The coin cells were charged in a constant current $(1 \mathrm{C})$-constant voltage regime $(4.2 \mathrm{~V})$ regime for $1 \mathrm{~h}$ and then discharged to $3.0 \mathrm{~V}$ at a constant current of $1 \mathrm{C}$. The discharge capacity is expressed on the basis of the mass of $\mathrm{LiCoO}_{2}$ as a cathode. The discharge capacity in the EC-EA binary system decreased rapidly from $100 \mathrm{mAhg}^{-1}$ to $20 \mathrm{mAhg}^{-1}$ after the 20th cycle. The discharge capacity in the EC-2FEA binary system was considerably higher than that in the EC-EFA binary system. The use of 2FEA as the alternative low-viscosity solvent remarkably suppressed the discharge capacity fading at high cycle numbers. The cathodic decomposition of the 2FEA-based solutions on lithium anodes can form passive thin films containing adequate amounts of organofluorine compounds. Although the organofluorine compounds have not been identified, lithium ions may readily pass through the surface film. The possible organofluorine compound in the surface films is monofluorinated lithium alkylcarboxylate. It is known that lithium alkylcarboxylate (RCOOLi) is formed on electrode surfaces by 


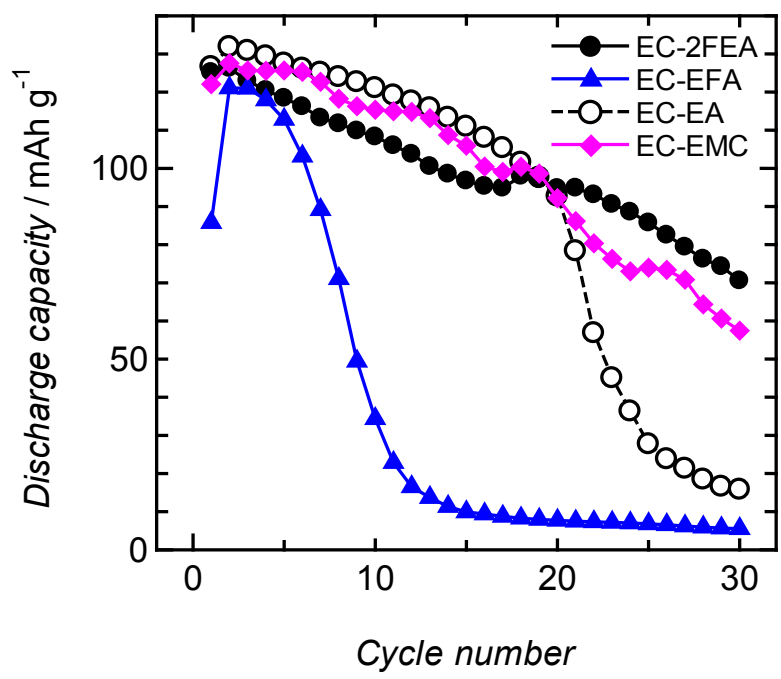

Figure 7. Variation of discharge capacities of $\mathrm{Li} \mid \mathrm{LiCoO}_{2}$ coin cells with respect to the cycle number at $25^{\circ} \mathrm{C}$. Electrolyte solutions are the same as described in the caption of Figure 5(b). The coin cells were charged in a constant current $(1 \mathrm{C})$ mode and further charged to keep constant voltage $(4.2 \mathrm{~V})$. Total charging time was set to $1 \mathrm{~h}$. The coin cells were then discharged to $3.0 \mathrm{~V}$ at the constant current $(1 \mathrm{C})$.

cathodic decomposition of nonfluorinated esters [22].

\section{Conclusion}

The use of two monofluorinated EAs allows us to investigate the effect of position isomerism on the physical and the electrochemical properties. The molar concentration decreased in the following descending order: 2FEA > EFA $>$ EA $>$ EMC. The molar concentration dominated the order of the mass densities of EA and its derivatives: 2FEA $>$ EFA $(>$ EMC) $>$ EA. The relative permittivity of EFA was higher than that of 2FEA, whereas the viscosity of EFA was lower than anticipated from the relative permittivity: EFA $>2$ FEA $>$ EA $>$ EMC for the relative permittivity and 2FEA $>$ EFA $>$ EMC $>$ EA for the viscosity. The conductivity of 1 moldm $^{-3} \mathrm{LiPF}_{6}$ solution in EFA was higher than that in 2FEA. The conductivity in 2FEA was higher than that in EA above $65^{\circ} \mathrm{C}$. The use of an EC-2FEA equimolar binary solution remarkably suppressed the cycling efficiency fading. The use of 2FEA as a co-solvent greatly improved the discharge capacity of a $\mathrm{Li}^{2} \mathrm{LiCoO}_{2}$ coin cell after the 20th cycle. 2FEA is a prominent candidate for co-solvents in lithium secondary batteries.

\section{Acknowledgements}

We would like to thank Mitsubishi Chemical Group Science and Technology Research Center for a donation to this work.

\section{References}

[1] Riddick, J.A., Bunger, W.B. and Sakano, T.K. (1986) Organic Solvents: Physical Properties and Methods of Purification. 4th Edition, Wiley-Interscience, New York.

[2] Yamaki, J. (2002) Advances in Lithium-Ion Batteries. In: van Schalkwijk, W.A. and Scrosati, B., Eds., Liquid Electro-Lytes, Chap. 5, Kluwer Academic/Plenum Publishers, New York, 155-183.

[3] Aurbach, D. and Schechter, A. (2004) Lithium Batteries, Science and Technology. In: Nazri, G.-A. and Pistoia, G., Eds., Advanced Liquid Electrolyte Solutions, Chap. 18, Kluwer Academic Publishers, Boston, 530-573.

[4] Ue, M. (2000) Richiumu-Ion Niji-Denchi, Zairyo To Oyo. 2nd Edition. In: Yoshio, M. and Kozawa, A., Eds., Yukidenkaieki No Yoekikagaku, Chap. 6, Nikkan Kogyo Shimbun Ltd., Tokyo, 83-98. (In Japanese)

[5] Takehara, M., Tsukimori, N., Nanbu, N., Ue, M. and Sasaki, Y. (2003) Physical and Electrolytic Properties of Fluoroethyl Methyl Carbonate. Electrochemistry, 71, 1201-1204.

[6] Nanbu, N., Takehara, M., Watanabe, S., Ue, M. and Sasaki, Y. (2007) Polar Effect of Successive Fluorination of Di- 
methyl Carbonate on Physical Properties. Bulletin of the Chemical Society of Japan, 80, 1302-1306. http://dx.doi.org/10.1246/bcsj.80.1302

[7] Tsukimori, N., Nanbu, N., Takehara, M., Ue, M. and Sasaki, Y. (2008) Electrolytic Properties of Ethyl Fluoroethyl Carbonate and Its Application to Lithium Battery. Chemistry Letters, 37, 368-369. http://dx.doi.org/10.1246/cl.2008.368

[8] Nanbu, N., Takimoto, K., Suzuki, K., Ohtake, M., Hagiyama, K., Takehara, M., Ue, M. and Sasaki, Y. (2008) Temperature Dependence of Physical Constants of Monofluororinated Propylene Carbonate as Highly Polar Liquid. Chemistry Letters, 37, 476-477. http://dx.doi.org/10.1246/cl.2008.476

[9] Nanbu, N., Takimoto, K., Takehara, M., Ue, M. and Sasaki, Y. (2008) Electrochemical Properties of Fluoropropylene Carbonate and Its Application to Lithium-Ion Batteries. Electrochemistry Communications, 10, 783-786. http://dx.doi.org/10.1016/j.elecom.2008.02.031

[10] Nanbu, N., Watanabe, S., Takehara, M., Ue, M. and Sasaki, Y. (2009) Electrolytic Characteristics of Fluoromethyl Methyl Carbonate for Lithium Rechargeable Batteries. Journal of Electroanalytical Chemistry, 625, 7-15. http://dx.doi.org/10.1016/i.jelechem.2008.09.022

[11] Nambu, N., Nachi, T., Takehara, M., Ue, M. and Sasaki, Y. (2012) Structural Isomerism Effect on Physical and Electrochemical Properties of Monofluorinated Linear Carbonates. Electrochemistry, 80, 771-773. http://dx.doi.org/10.5796/electrochemistry.80.771

[12] Nanbu, N., Suzuki, Y., Ohtsuki, K., Meguro, T., Takehara, M., Ue, M. and Sasaki, Y. (2010) Physical and Electrochemical Properties of Monofluorinated Ethyl Acetates for Lithium Rechargeable Batteries. Electrochemistry, 78, 446449. http://dx.doi.org/10.5796/electrochemistry.78.446

[13] Nambu, N., Ohtsuki, K., Mutsuga, H., Suzuki, Y., Takehara, M., Ue, M. and Sasaki, Y. (2012) Use of Monofluorinated Ethyl Propionates as Solvents for Lithium Secondary Batteries. Electrochemistry, 80, 746-748. http://dx.doi.org/10.5796/electrochemistry.80.746

[14] Nakajima, T., Dan, K., Koh, M., Ino, T. and Shimizu, T. (2001) Effect of Addition of Fluoroethers to Organic Solvents for Lithium Ion Secondary Batteries. Journal of Fluorine Chemistry, 111, 167-174. http://dx.doi.org/10.1016/S0022-1139(01)00449-3

[15] Yamaki, J., Yamazaki, I., Egashira, M. and Okada, S. (2001) Thermal Studies of Fluorinated Ester as a Novel Candidate for Electrolyte Solvent of Lithium Metal Anode Rechargeable Cells. Journal of Power Sources, 102, 288-293. http://dx.doi.org/10.1016/S0378-7753(01)00805-9

[16] Sato, K., Yamazaki, I., Okada, S. and Yamaki, J. (2002) Mixed Solvent Electrolytes Containing Fluorinated Carboxylic Acid Esters to Improve the Thermal Stability of Lithium Metal Anode Cells. Solid State Ionics, 148, 463-466. http://dx.doi.org/10.1016/S0167-2738(02)00088-7

[17] Ihara, M., Hang, B.T., Sato, K., Egashira, M., Okada, S. and Yamaki, J. (2003) Properties of Carbon Anodes and Thermal Stability in $\mathrm{LiPF}_{6} /$ Methyl Difluoroacetate Electrolyte. Journal of the Electrochemical Society, 150, A1476A1483. http://dx.doi.org/10.1149/1.1614269

[18] Kawamura, T., Tanaka, T., Egashira, M., Watanabe, I., Okada, S. and Yamaki, J. (2005) Methyl Difluoroacetate Inhibits Corrosion of Aluminum Cathode Current Collector for Lithium Ion Cells. Electrochemical Solid-State Letters, 8 , A459-A463. http://dx.doi.org/10.1149/1.1993367

[19] Koch, V.R. and Brummer, S.B. (1978) The Effect of Desiccants on the Cycling Efficiency of The Lithium Electrode in Propylene Carbonate-Based Electrolytes. Electrochimica Acta, 23, 55-62. http://dx.doi.org/10.1016/0013-4686(78)87033-9

[20] Uneyama, K. (2006) Organofluorine Chemistry. Blackwell Publishing, Ltd., Oxford. http://dx.doi.org/10.1002/9780470988589

[21] Andrade, E.N. da C. (1930) The Viscosity of Liquids. Nature, 125, 309-310. http://dx.doi.org/10.1038/125309b0

[22] Aurbach, D. and Cohen, Y. (2004) Lithium-Ion Batteries. Solid-Electrolyte Interphase. In: Balbuena, P.B. and Wang, Y., Eds., Identification of Surface Films on Electrodes in Non-aqueous Electrolyte solutions: Spectroscopic, Electronic and Morphological Studies, Chap. 2, Imperial College Press, London, 70-139. 